\title{
دراسة تحليلية لبعض مصطلحات التأويلية عند غادامير
}

\author{
خالد أحمد السباعي \\ كلية الآداب - جامعة مصراتة
}

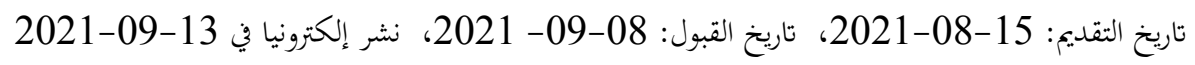
https://doi.org/10.36602/faj/2021.n.18.06

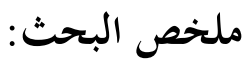

لئن كان لكل علم مصطلحاته الخاصة به، فكذلك للفلسفة مصطلحاتها ولو أن الفلسفة هي فكر

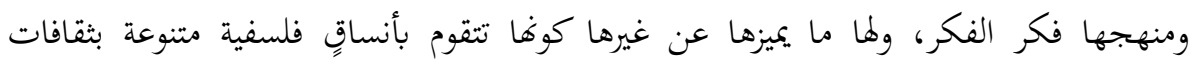

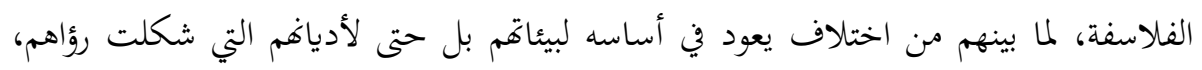

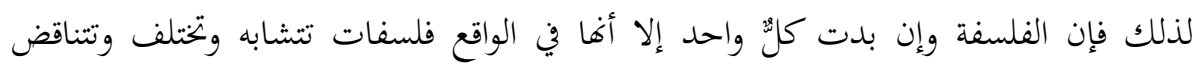

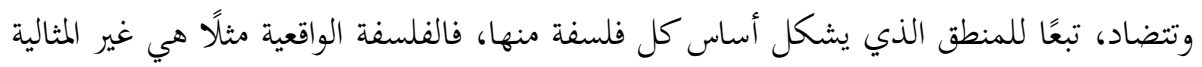

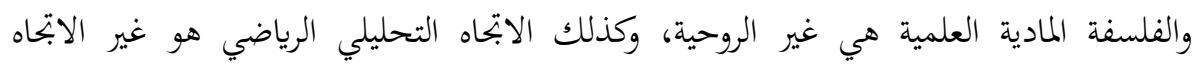

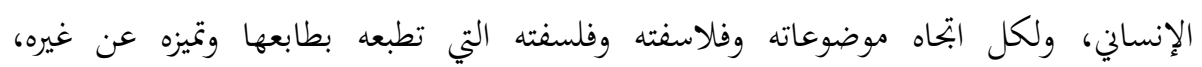

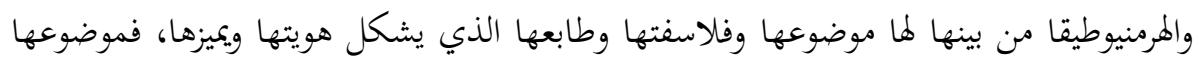

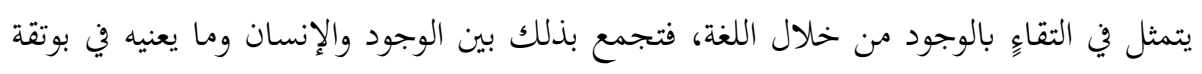

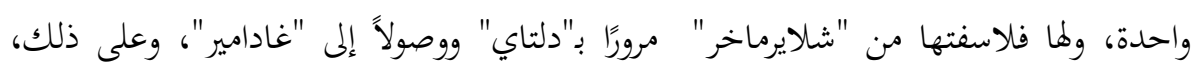

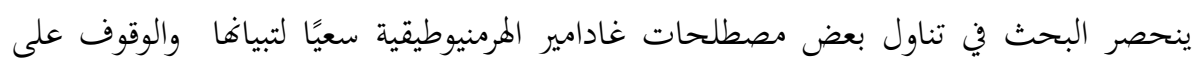
مضامينها ودلالاتا، خاصة وأنه تقدم بالهرمنيوطيقا خطوة للأمام حينما أخذها إلى الى المرحلة

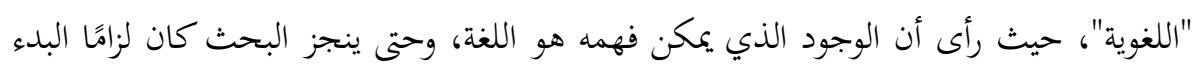
بشيء من التوضيح عن نشأة الهرمنيوطيقا، وسمات المصطلح الفلسفي عمومًا. الكلمات المفتاحية: التأويل، الفهم، الوعي، نص، المؤول، متلقي.

khaledsebaie31@art.misuratau.edu.ly ${ }^{1}$ 


\title{
A Study in some of Gadamer's Hermeneutic Terms
}

\author{
Khaled Sebaie \\ Faculty of Arts, Misurata University
}

\begin{abstract}
Each of sciences has its own terminology, so also philosophy has its own, even if philosophy is thought and its method is the thought of thought. Philosophy has what distinguishes it from other sciences as it is based on various philosophical systems, doctrines and trends, with the diversity of the philosophers cultures, due to the difference between them that is mainly due to their cultures, even to their environments and religions that formed their visions and philosophies, therefore, philosophy in general, although it is seen by those who do not specialize in it as having a common orientation, but in reality are disciplines that have similarities, differences and even contradictions, according to the logic that forms the basis of each philosophy, for example, realistic philosophy is not idealistic one, and scientific materialist philosophy is not a bio-spiritual one. Likewise, the analytical-mathematical trend is not the human one, for each trend has its themes, its system, its philosophers, and its philosophy that characterizes it with its character and distinguishes it from others, its subject is a meeting with existence through language, thus combining existence and man, the worlds of man and what he suffers and what he aims for in one crucible. Hermeneutics has its philosophers from "Schleirmacher" through "Dilthey" to "Gadamer". Accordingly, the research is limited to dealing with some of "Gadamer's" hermeneutic terms, in an effort to clarify them, reveal their ambiguity, and determine their implications and connotations, especially since he made hermeneutics a step forward when he took it to the "linguistic" stage, when he saw that the existence that can be understood is language.
\end{abstract}

Keywords: Interpretation, Understanding, Consciousness-Text, Interpreter, Perceiver 
1

تعد الهرمنيوطيقا أو نظرية التأويل وممارسته الاتحاه الأقدم فلسفيًا في سبر غور النصوص وكشف كنهها، فكل مصطلح يمتلك تصريمًا ظاهرًا في الوقت الذي يمتلك أيضًا تلميحًا مخبوءًا يهفز على المشاركة لإظهاره، وهذه المشاركة لا تُنتظرُ من غير القارئ الزاخر المؤثث الذهن(1)، المتقد بالمؤهلات الفكرية والمهارات اللسانية وحتى غير اللسانية والكفاءات اللغوية التي تهيئ للممكن والمتخيل، وكذلك لديناميكا التنقل بين ماضٍ فات، وحاضر وآت، التي من شأفها تأهيله بالمقدرة على استجواب النصوص واستنطاقها وإبراز ما تحويه من مسكوتٍ عنه يأبى التجلي بالتصريح والتلميح أحيانًا، ولا غرو في ذلك مادامت الهرمنيوطيقا هي التأويل بما يعني حمل اللفظ على المعنى المجازي أو الاستعاري أو الكنائي أي بما هو مضمر ومستور، وللهرمنيوطيقا مصطلحاتها الملمغزة الدالة على هوية الفكرة التي تحملها وتريد تبليغها، هوية التأويل والتطبيق في آنٍ معًا، ومصطلحات "أنا" و"أنت" وما بينهما من علاقة تَسم الوعي التاريخي. 1.1

يستقصي هذا البحث بالدراسة والتحليل بعض مصطلحات غادامير الهرمنيوطيقية، من حيث كوفها تمثل مصطلحات تربط بين الوجود واللغة، ويبحث في سياقها الفلسفي الذي ارتبط فيه ما هو إنساني مض باللغة والفهم والتاريخ والواقع، وكشف براعة غادامير في جعل الذاتية "مركزية" في عمليتي الفهم والتأويل، التي لا تتم بمعزل عن التاريخ بمكوناته

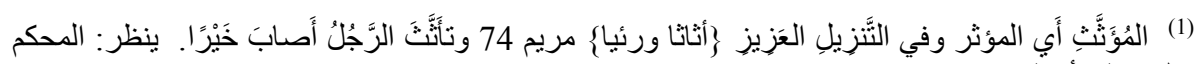
و المحيط الأعظم (171/ 171). 
الثلاث (الماضي والحاضر والمستقبل)، تلك الذاتية التي يراها تصوغ كيان المتلقي وفهمه ولن تنزاح جانبًا مهما حاول الفكاك عنها، فما الذي يمكنه القيام به إزاء وضعه هذا؟ 2.1

يستمد البحث أهميته من أهمية موضوعه الذي يسعى للوقوف على معانيه ومضامينه، ذلك أن الوقوف على معاني مصطلحات فلسفة ما، هو في بعده الأقصى وقوف على هويتها وطابعها الذي يميزها عن غيرها، كما أنه وقوف على آلية تمثل عنوانا وطريقة التعامل معها وتوظيفها، فمصطلحات كل فلسفة تتضمن توجهاها ورؤاها ووجهات نظرها وتوقعاتها، ومن تم بحث توظيفها والاستفادة منها. (

الهدف العام، ويتمثل في إثراء البحث الفلسفي في مجال المصطلحات الفلسفية، والهدف الخاص يتمثل في محاولة الوقوف على معالٍ لمصطلحات فلسفية هرمنيوطيقية، وبحث الكيفية التي صِيغت بها هذه المصطلحات تنقلاً بين الفهم واللغة من جهة، وتبيين دور المشاركة الذاتية في ذلك من جهة أخرى بفضل ما تنطوي عليه الذات من مؤهلات تملكها، ويمكنها توظيفها وصولًا لإِبداع التوليدي.

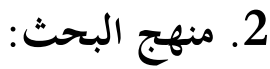

يرتبط منهج البحث ارتباطًا وثيقًا بموضوع الدراسة لمناسبته له، وهو المنهج الفلسفي التحليلي التركيبي الذي يتمثل في تحليل المصطلح، ومن ثم استنتاج مضمونه، كما استخدم المنهج التاريخي أحيانًا نظرًا لما يقتضيه تتبع تاريخ المصطلح إذ لكل مصطلح تاريخه، مع اللجوء أحيانًا للمنهج المقارن متى اقتضى الأمر ذلك. 
3. الهرمنيوطيقا أو نظرية التأويل:

\section{3}

الثابت أن لنشأة الهرمنيوطيقا صلة وثيقة بدورها ووظيفتها، فقد عرفت لأول مرة في

اليونان القديمة مقرونة بالفعل Hermeneuin الذي يعني تأويل المرتبط تاريخيًا برسول مجمع "آلةة" “Pantheon” في الأولمب الذي كان يبلغ رسائل تلك الآلمة للبشر، يحمل إليهم ما هو خافٍ عنهم، وهو في نظرهم مُلمٌّ بلغة الآلمة ورموزها ناهيك عن لغة البشر ومقاصدها، ولذلك صار كل ما احتاج لتأويل من بلاغ أو نص هو في جملته من مُلْقِ إلى متلقٍ، أو من مُنتمٍ لعالم إلى مُنتمٍ لعالم آخر، إنه نقطة التقاء لخفاء سابق مع باحث لاستظهاره، كتلك التي بين "عالم النص وعالم القارئ، وبالتالي فهناك حاجة دائمًا لهرمس لكي "يترجم" من أحد العالمين إلى الآخر" (عادل مصطفى،2018 ،ص27)، وأن تؤول To interpret القادرة على التعبير بعد أن أجرى المؤول لذاته "موضعة ذاتية" “Objectification" تمكنها من إظهار ما هو حبيس عالمه الخاص للعلن، أي أن تنتقل من المحتوى الظاهر إلى المضمون الكامن المخفي، وذلك من خلال فك كل الرموز والإشارات والإيحاءات سواء كانت محددة المعنى Univocal أو متعددة أي ملتبسة المعنى Equivocal حسب تصنيف "ريكور" بما فيها تلك التي في الأحلام، وحتى يتسنى ذلك، فإنه لابد من الممارسة الهرمنيوطيقية التي تكفل التنقل السلس بين الماضي والحاضر، خاصة وأن طبيعتها تعطينا الأساس لكوها "لم تكن أبدًا سكونية، إذ إن الكيفية التي نقرأ بها النصوص ونفهمها هي متغيرة باستمرار، تمامًا كما يتغير فهمنا لأنفسنا" (دافيد جاسبر،2007،ص22)، 
فديناميكيتها "حركتها" هي بمنزلة استعادة للوعي القادر على ضم آفاق الزمان بأبعادها الثلاثة ووضعها على مشهد ممتلئ بالحياة بعد أن أخذ بشتى نواحي بجامع الوعي عليه. 2.3

يتميز كل مصطلح بأنه يملك اتحادًا لا يقبل الفكاك بين مفهومه وصورته، خاصة وأن كلمة منطوقة تتضمن فكرة ربما تمتُّ بصلة للعقل أكثر من الحس أو بالعكس، إلا أنه رغم ذلك يظل أولًا وأخيرًا مفهومًا يحمل نوعًا من الوجود، ويمثل صورة تعبر عنه، وبما أنه كذلك فهو كالكائن الحي مقدرًا له أن يكون له عمره الذي قد يمتد به لعصور أو يكون رهن عصره فحسب، كما أنه قد يغيب لقرون، ويعود في أحياٍٍ أخرى ليبقى ويخظى بأهمية بالغة كمصطلح الديمقراطية مثلًا الذي ملأ الفلسفة السياسية منذ عهد "سولون الأثيني" "Solon“" (640-560 ق.م) إلى قتل الفيلسوف سقراط وهجوم أفلاطون عليها وأرسطو، وظل قرونًا طويلة غائبًا حتى القرن السابع عشر الميلادي، ليشهد المصطلح عودته مع عهد "العقد الاجتماعي" وانتعاشه من جديد، وكل مصطلح له تاريخه الذي يشهد بميلاده ودوامه وزواله وعودته إن كانت له عودة، وعليه، فإن مهمة تتبع مسيرة المصطلحات لقدر ما تبدو رائعة فإنها بالقدر ذاته تنطلي على شيء من التعقيد، الذي يتطلب الوقوف على كنهه والظروف التي نشأ فيها سواء من حيث الزمان أو المكان، ثم إن المصطلح يحدث أن يهاجر من فكر إلى آخر، و من زمان إلى آخر، فمصطلح "متفائل" مثلا كان قد استخدمه العلماء اليسوعيون لأول مرة، ثم حدث أن تناوله الفيلسوف لاينتز حينما ألف كل "مذكرات تريفو" “Memoires de Trevoux" وترسخ حتى صار وصفًا له "فيلسوف التفاؤل" حينما جمع أعماله في مؤلفه "العدالة الإلهية" “Theodicee” Natura " الذي صدر عام 1710م، كذلك الحال مع مصطلح "الطبيعة الطابعة" 
naturans بالأساس مصطلح مهاجر من العبية إلى اللاتينية كما أوضحت الدراسات بعد ترجمة أعمال الفيلسوف "ابن رشد".

وعلى ما تقدم فإن مصطلحات الهيرمنيوطيقا ليست استثناءً من حيث ما جرى على مصطلحات الفلسفة عمومًا، فإذا كان لكل مذهب أو نسق أو تيار مصطلحاته الدالة عليه فإن للهرمنيوطيقا مصطلحاتها الدالة عليها، وهذا السبب كثيرًا ما رأينا الفلاسفة يشكون من أفم لا يفهمون بعضهم بعضا، خاصة وأن لكل منهم مصطلحاته المتخصصة التي تأخذ على عاتقها تبيان الدلالة الدقيقة لمفهوم من المفاهيم التي يريد إيصالها، ولذلك نجد أحيانًا مصطلحات بما يعنيه "علم المصطلحات" “Terminology" من معنى خاصة بفيلسوف دون غيره لفهم فلسفته، والأمثلة على ذلك كثيرة، لعل أولها وأقدمها محاولة أرسطو المتمثلة فيما قدمه من بيان للمشترك اللفظي، والترادف وانتقاء الكلمات التي لا تعتمد المحورية البشرية غير المبررة، وضرورة إيجاد مصطلحات تقنية تلبي الحاجة إلى الدقة التي تتوافق مع المنهجية العلمية، وهكذا، تتوالى المحاولات سواء من الفيلسوف نفسه أو من غيره لفهمه، فصرنا نرى فيما بعد مصطلحات فلسفية خاصة بـ"كانط" وأخرى خاصة ب"هيجل" وغيرها بـ"هايدجر"، وبالفيلسوف الذي قيد دراستنا، مع الأخذ في الحسبان أهما ليست مصطلحات تقف عند بيان مراده فحسب، بل تتعداه أحيانًا لتبين رؤية النسق الذي يمثله بأسره، وتصير عنوانًا له، وهذا لا يعني بأن ذلك يشكل غموضًا للفيلسوف أو لرون لنسقه يبعده عن الحياة، بل بالعكس تقدم إيضاحًا عن جوانب غامضة فيه، أو ربما لم يتم التطرق إليها، خاصة عندما كان ينقل معرفة جديدة من شأفها العمل على تنظيم فكرة ما 
، ومن ثم الربط بينها وبين غيرها، فدراسة مصطلحات فلسفة من الفلسفات تعطيها تخصصها ، وتؤكد هويتها، وترسخ طابعها الذي يميزها عن غيرها. والمصطلحات التي استهدفت بالدراسة تبعًا لأهميتها هي كالآتي:

\section{1- الدائرة المرمنيوطيقية: The Hermeneutic Circle}

وهي أن ما يكتنزه المؤول من خبرات وفهم تكون بمنزلة المؤهلات التي تمكنه من "الفهم سلفًا" “Fore-understand” من خلال رده كل ما يواجهه لها، كمرآة يعكس عليها ما يقع تحت اهتمامه، فمثلاً عندما يتناول نصًا بالقراءة، فإنه يتناوله بتوقعات معينة مرسومة سلفًا، وهذا ما يعرف بالإسقاط المسبق Fore-projection الذي ينبغي له أن يراجعه على الدوام، ذلك أن كل مراجعة لإسقاط من شأها تقديم إسقاط جديد من المعنى، ويحدث أن تصطف الإسقاطات المتنافسة، فينتج عن اصطفافها أن يصير المعنى أكثر بحليًا، على أن هذه العملية المتواصلة في كل مرة تنفتح على إسقاط جديد، وهكذا، يفضي كل إسقاط على آخر، وهذه الحركية هي في جوهرها حركة الفهم والتأويل "فهذه العملية المتواصلة لإسقاط جديد من شأفا أن تشكل حركة الفهم والتأويل" (Gadamer, 2006,p.269)، وحتى يصل المؤول لمرحلة الإبداع عليه أن يعرف كيف يعود من النص إلى ذاته، متفحصًا إياها بالبحث عن المعاني المسبقة التي ينطوي عليها حتى يبلغ أقصى فهم ممكن، وهذا يتم في عملية متبادلة تتمثل في محاورة النص الذي يخفي عوالم متعددة ، ثم يعود لذاته ليحاورها، وبالتالي فإن دائرية الأحكام المسبقة لا غنئ عنها في سبيل إحراز فهٍِ تأويليّ على الإطلاق. 


\section{2- الموضوع الجمالي: Aesthetic Object}

كل عمل فني أو جمالي له موضوعه الذي يحمل دلالة ما، لا معنى لها إلا متى بتحلى لذات تقوم باستعراضه وتمعنه، فيصير بذلك مدرًا ؛لكونه بالأساس قابلا للإدراك بما يحمله من قصديات ضمنية تنفتح على الآخر وبتذبه إليها، فتحدث لحظة التفاعل من الآخر ولن تبقي لهذا العمل قصدياته الكامنة فيه، بل سيكتسب دلالات أخرى بفعل الانسجام معه من قبل المتفاعل بعد تفكيكه وإعادة بنائه ، فتصير دلالات العمل متجددة، فالموضوع الجمالي ليس "كيانًا منفصلًا ، ولا ينبغي التعامل معه على هذا النحو، لما له من أصالة Chris ( تمارس سطوةًا على القارئ والمؤول أو المشاهد فيصير "حدثًا" نحن نشارك فيه Lawn \& Niall Keane,2011,p.9 التخمينات وتصورات من شأخها استدعاء كل ما فيه من المعاني المخفية انطلاقًا من كونه أثرًا يمكن اكتشافه من جديد، طالما كل ما فيه من أسلوبية، وسبك لألفاظ تسيغ ممارسة الفعل التأويلي عليه، فكل موضوع جمالي هو في حالة وحدة مع متلقيه يُحدِثُ فهمًا تصوريًا سواء كان نصًا أو لوحُة، وما من شك أن كل ما يتمناه من قدم عملاً ما ، ولتكن رواية مثلًا، هو أن يجد من يتلقاه، ويمتلك المهارات اللغوية والذائقة الفنية والبراعات اللسانية للتفاعل معه، فهذه جميعًا "قدرات تواصلية تمكنه جميعها من فهم النص و تأويله ، إنه متلق مثالي ينشده الراوي" (محمد القاضي،2010 ، ص318).

\section{3- توقع المعنى: Anticipation of Meaning}

هو فهم القارئ معنى كاملا من خلال جزء من النص، وبالعكس فهم جزء من النص من خلال المعنى الكامل، و والواقع أن النص لا يتم معناه بمجرد فهم جملة أو عبارة منه، وهذا فيما يرى غادامير يعود لقاعدة تأويلية ناشئة عن بلاغة قديمة، من شأها أن 
توقعنا فيما أطلق عليها بـ"العلاقة الدائرية" A circular relationship ، والذي

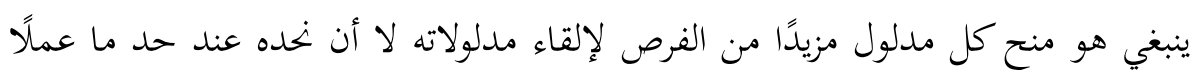

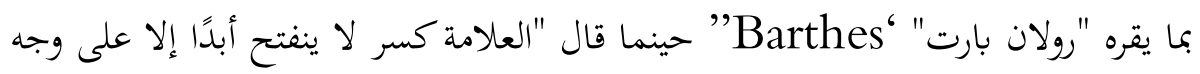
علامة أخرى"R. Barthes,1970, p.72) ) ، وعلى أية حال، فإن كمال فهم المعنى غالبًا وفقًا لغادامير تعرقله مقاومة النص التي تتضمن توترات تنفرض بغعل الزمان والمكان على أقل تقدير، خصوصًا عندما يتداخلان في ذاكرة المتلقي فينتهيان به لنهاية ربما

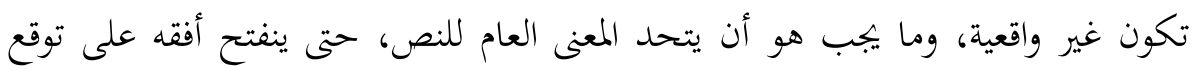

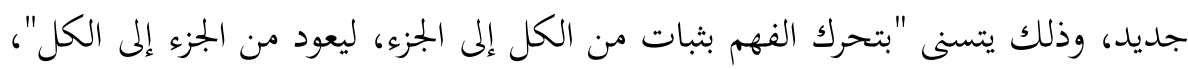

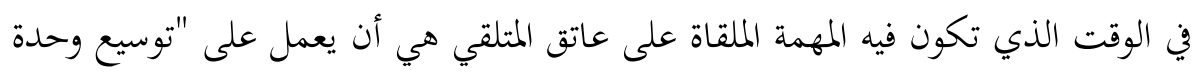
المعنى وبسطها" (Gadamer, 2006,p.291) ويحدد غادامير هنا معيارًا للفهم الصحيح في شكل نتيجة تحدث جراء التناغم "بين جميع الأجزاء مع الكل"، أما معيار الفشل يكمن في انعدام التناغم الذي يعني ضمنًا أن تفاعل المتلقي على مستوى الفهم لم لم يحدث أن اتفق فيه ما هو واقعي مع ما هو ممكن وبالتالي حدث الإخفاق. 4- (إن الوجود الذي يمكن أن يكون مفهومًا هو اللغة)

Being that can be understood is language عبارة يقصد من ورائها غادامير أن الوجود يكمن وراء اللغة ويتجاوزها، وهو من يعطي لها الإمكان، وبعبارة أخرى، ثُمة أولوية للغة على التفكير، وليس للتفكير على اللغة، ونهاء

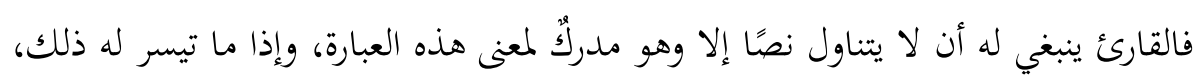

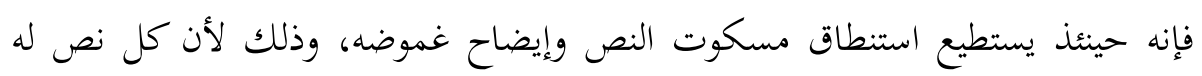

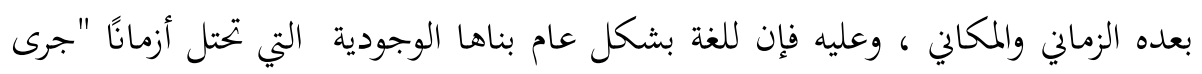


تفعيلها من خلال إعطائها أصواتًا فيها بفعل التجربة ، وعليه فإن علاقتنا بالعالم جرت في ضوء الفهم والتأويل، وهذان الخيطان المتشابكان دائمًا ما تتوسطهما اللغة، وبعبارة أخرى، Chris Lawn \& Niall ( ) تلعم اللغة العلاقة التفسيرية المفهومة للإنسان مع العالم (Keane,2011,p.88)، وهنا لابد من الإشارة إلى أن لكل صوت ملفوظ بنية تحمل تصورا له معنى يقصده، قد لا يتجلى إلا بإضافة ألفاظ أخرى له.

\section{5- -5 حلقات الحياة التاريخية المغلقة: Closed circuits of historical life}

هي ما تتضمنه الذاتية من حضور للأشياء والموجودات حدثت بفعل تراكم خبراتا الماضية بها فصارت كما لو أها مرجعية ذاكراتية لها، تشدها كلما تناهى وعيها أو إحساسها بما يماثله، وهذا ما قصده غادامير بالمصطلح لما كان مرتبطًا بوعي الفرد الذي يعد مجرد ومضة في حلقات الحياة التاريخية المغلقة، فتصير مثلاً عبارة ما مرتبطة في وعيه بأخرى مخبوة بفعل ماضيه الخبراتي، وقد بنى عليها حكمًا أو ارتبطت عنده بأحكام وتحيزات، تصير تستدعى كلما صادف عبارة تشبهها أو ترتبط بها بصورة ما، أو كمثال آخر، مشهد ترسخ في تصوراته ن وقد ارتبط بحدثٍ أو حتى ترنيمة ما يظل فيما بعد كلما صادف ما يشبهه يعيده لذلك السابق وبما اقترن به، ويجري استحضار الوعي السابق هنا دون شعور من الفرد، إها كومضة تظهر في منطقة الوعي متى ما تمثل أمامه ما يستدعيها للحضور Constitute the " ثانية، ولذذه فيما بعد ينسب غادامير تشكل "حقيقة وجوده التاريخي (historical of his being” " (Gadamer, 2006,p.278)، وأثرها على الذات يتمثل في أها تظل تشد الفرد إليها، فتؤثر على أحكامه كما أها ربما تفتح أمامه سلسلة من الاحتمالات والإمكانات عند قراءته لنصٍ ما مثلًا ، خاصة وأن أي فن من الفنون هو "شكل مغلق في تفرده وككل كامل عضوي متوازن، وفي الأثناء يشكل منتجًا مفتوحًا 
بسبب قابليته للتأويلات المختلفة التي لا تعد ولا تحصى، ولا تمس خصوصيته التي لا تقبل التغير، ذلك أن كل تلقِّ أو استقبال لعمل فني هو تأويل وأداء له، حيث في كل استقبال يأخذ العمل منظورًا جديدًا لنفسه"(Umberto Eco,1989,p 4.)، فالمتلقون بلا شك يختلفون في وعيهم ورؤاهم، وما يحضر لمم من صور ذهنية.

\section{6xperience : الحبرة:}

هي اللحظة من الزمان التي تنتمي لمرحلة تاريخية معينة، قُدِّمَ في حينها نصٌٌ مقروءٌ معينٌ أو عملٌٌ فنيٌّ ما، من شأخها أن تعمل على التقاء الملقي والمتلقي/ المؤول والموّوِول/ النص والقارئ، يكون فيها الثاني مزودًا بخبرة تأويلية إلى جانب ما تنطوي عليه ذاته من تحيزات تمثل فهمه المسبق Pre-understanding هذه الخبرة التأويلية تمكنه من خلالها تمييز ما وقع في دائرة اهتمامه تاريخيًا، أي يفهم الموقف /الوضع /اللحظة التاريخية التي أنتج فيها العمل الذي هو قيد اهتمامه، إها بالنسبة للموّوِول بمنزلة تمثيل واستحضار لعملية جرت في الماضي، وفي الوقت ذاته جر اللحظة التي هي الآن والرجوع بها للماضي، لذلك فكل عمل بما في ذلك الفني منه، ينطلق من الخبرات أو التجارب ولا يلبث حتى "يرتفع فوقها ليتجاوزها فيكتسب أهمية عالمية تتجاوز التاريخ" (Gadamer, 2006,p.xiii). وهذا لا يعفي القارئ/ الموّوِل أن يحيط بالظرف أو المقام الذي أنتج فيه ما هو بصدده سواء كان مقروءًا أو حتى ملفوظًا أو حتى مشاهدًا، فجزء من تفاعله تأويليًا معه لا يتم بل ربما يكون من المستحيل (إذا اقتصر السامع على الجملة وظل جاهلا بالمقام الذي نشأت فيه) " (محمد القاضي،2010 ، ص.ص 256-7)، فكل عمل نتج عن خبرة يمتلك انفتاحا في ذاته يجعله في حراك دائم يتجاوزها لغيرها، فكل خبرة في نظر غادامير هي ضمن مجال الفهم، سواء كانت علمية أو إنسانية أو فنية أو حتى فلسفية هي "في النهاية جانب من 
Circular“ "جوانب الفهم التأويلي من حيث إنه ينطوي على "بنية دائرية Chris Lawn \& Niall ) "structure (Keane,2011,p.154)، وعليه فإن كل خبرة "عمل" صدرت هي ليست رهينة بقاعدة مضبوطة وهمائية عملت على بتميدها للحظتها.

7- التحام أو انصهار الآفاق: Fusion of horizons

يقول غادامير: "ينم مفهوم الأفق على نفسه، لأنه يعبر عن سعة الرؤية العظمى Superior breadth (Gadamer, 2006,p.304). فالأفق هو في معناه الأبعد حسي، ويظل لغويًا إذ اللغة تمده بالانكشاف والحد ، والمرء مطالب بأن يحرز أفقًا ليس بالمعنى الذي يتبنى فيه وجهة نظر غيره أو أن يتقدصه عاطفيًا، بل عليه أن ينتقل مرتقيًا إلى شمولية أعلى متجاوزة لطبيعته الجزئية وطبيعة الآخر الجزئية كذلك لدرجة تذوب فيها الذات مع الموضوع

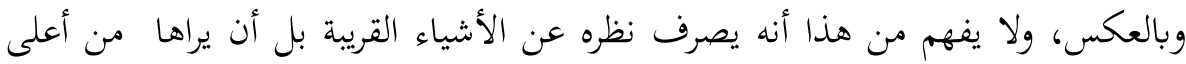

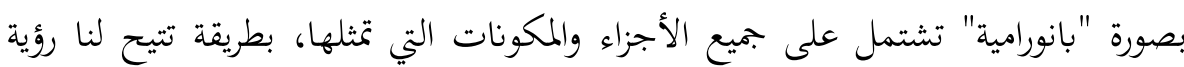
الذات، ورؤية الآخر التاريخي، فالأفق إذن هو طموح من نوع عال متحرك أبدًا إلا أنه رغم ذلك يستعصي على التحقق التام، ذلك لأننا لا يمكن أن ننجز الشفافية التامة نو الآخر، وعليه أكد غادامير أن انصهار آفاق التأويل لا يصل إليه المتلقي بصورة مطلقة، وذلك لما لمان كان متصفًا بالتغير الدائم، ولا يعرف الاستقرار على معنى بذاته، بل إنه كلما لاح منه

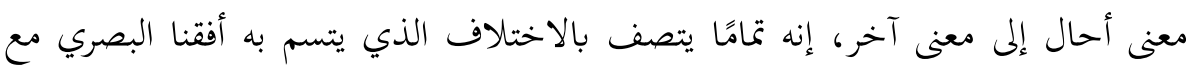
كل خطوة نخطوها (Gadamer,2004,p.61)، فكل أفق هو لذات كما كل قراءة 
هي لقارئ ، وهذا القارئ يقوم بنشاط "سميولوجي (علاماتي أو دلالي) متعدد الأطراف على حد تعبير "إيكو". - ميك.

8- 8 الوعي المتأثر تاريخيًا: Historically effected consciousness هو عنصر الفهم ذاته، ويؤثر في عملية إيجاد السؤال، هكذا بإيجاز يعرفه غادامير، لكن ما علاقته بالتاريخ؟ في الواقع أن كل وعي هو وعي متأثر بالتاريخ طالما أنه يعيش لحظته ، ويبحث في غيرها من الماضي، والثابت أن هذا الوعي هو وعي المؤول الذي يتضمن ماضيا تأويليا مؤثرا فيه، إنه ماضي ذاكرته التي تختزن معطيات ثقافية متنوعة وتوقعات وتخمينات تصير في حالة سيرورة لا تنتهي بمجرد التفاعل مع العمل الفني او الشروع في معالجة نصية ما، فكل عمل فني أو نصي يتضمن ما يشجع الوعي الذاتي التاريخي على المضي فيه، وذلك لما كان ذلك العمل أو النص يمتلك ديناميكية متحركة هي على المستوى الأبعد فعالية محفزة للوعي على أن ينفتح على عددٍ لا متناهٍ من التأويلات، فالمؤول هنا هو السائل الذي يطرح السؤال منطلقًا من ذاته وبالتالي "لن يتسنى له موقفٌ يكون فيه محايدًا بحيث يستجوب ما هو بصدده من عمل، ذلك أن موقع التأويل هو ذاته الماضي على الحاضر" (79.Chris Lawn \& Niall Keane,2011,p)، فيحصل أن يكون النص متضمنًا "لإحالة ما في محاولة لسد فجوة ما ربما تكون نتيجة لإضمار أو لحجب (محمد القاضي،2010 ، ص 15)، وعليه، فكل وعي هو وعي تاريخي أي متأثر بالتاريخ ، وبما يتضمنه من خبرات إذا ما وظفها ، تمكنه من تقديم رؤيته ونموذجه التأويلي، الفعل الذي تكون نتيجته إحداث التوالد في النص بما يحافظ على أصالته وخصوصيته. 


\section{9-الانطولوجيا: Ontology}

عند غادامير تستمد أساسها من أستاذه هايدجر (1889-1976)، وتخظى بقيمة جوهرية عنده حيث نلمس ذلك في مؤلفه "الحقيقة والنهج"، ففي الوقت الذي يؤكد

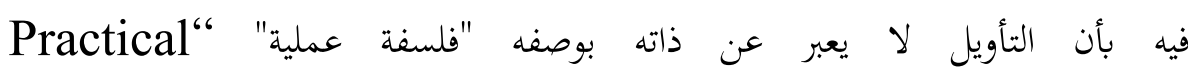
“philosophy

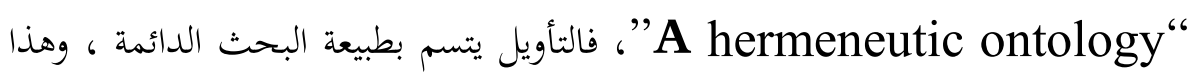
ما يقصده غادامير بالطبيعة الحوارية للتأويل، بسبب ما في بنية اللغة من تطور وتغير يعكس تأملاً من شأنه أن يعمل على انفتاح أو توسيع ما يطلق عليه غادامير "أفق الأنطولوجيا التأويلية" الذي لا يقف عن قيد ولا يحد بحد؛ لأنه ببساطة لا "إجراء رسمي" له، سوى أنه يثري ذاته “Self- perpetuating” بما يتمتع به من "ديناميكية" فعالة لا تفتر ولا تنقطع، وعليه فاللغة تلعب دورًا محوريًا في أية عملية تسعى نهو الكشف الأنطولوجي الذي لا ينفتح إلا باللغة، كما لا يمكن التعبير عنه إلا بها، واللغة من حيث هي كلمات منطوقة أو "أصوات يعبر بها كل قوم عن أغراضهم"(ابن جني، الخصائص ص.43) لذلك فهي في ماهيتها إجراء يتم بين ثلاثة مكونات أو عناصر هم مُخَاطَب ومخاطِب والأنطولوجيا التي

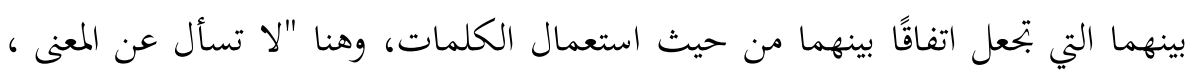
ولكن سَل عن الاستعمال" (Janet Fodor,1977, p.19 ) ، فالاستعمال هو الفعل أو العمل الذي يأخذ صورة من الصور التي من طبيعتها إما الانفصال و وإما الاتصال، وعلى أية حال، ما كان لغادامير أن يطور أنطولوجيا اللغة لو لم يقم هايدجر بتفكيك تاريخ الأنطولوجيا، وبذا التطوير يستقيم القول بأن غادامير تمكن من القضاء على البعد أو الانقسام خصوصًا ذلك الذي بين الذات والموضوع. 


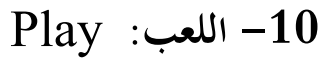

تحتل فكرة اللعب مكانة رئيسة بشكل خاص في مؤلف غادامير "الحقيقة والمنهج" خصوصًا فيما يتعلق بالجماليات، فقد سعى للتحول بهذه الفكرة من النحو الذي كانت

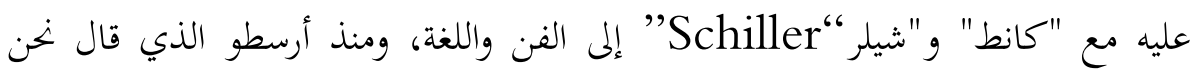

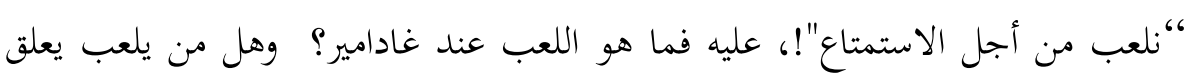
الجدية جانبًا خاصة وأن اللعب يتضمن جديته الخاصة؟ الحقيقة أن اللعب عند غادامير هو

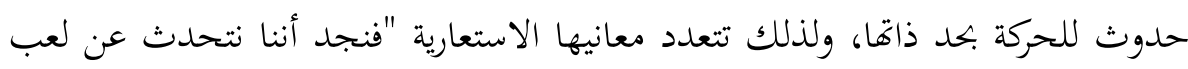
الضوء، ولعب الموج، ولعب لمعشق تروس الناقل للحركة في آلة، وكذلك تفاعل لأطراف جadamer, ) جسم الإنسان، ولعب القوى، ولعب البعوض، وحتى لعب الكلمات

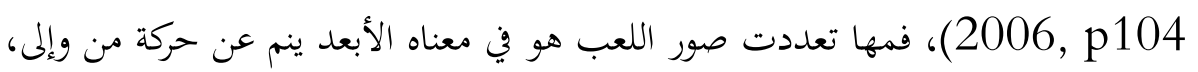

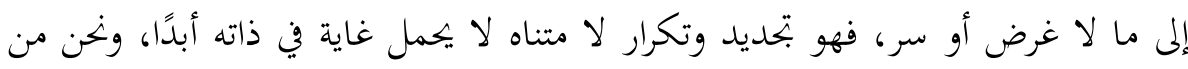
نقوم بربط "ظواهر كظاهرة اللعب بحقل الذاتية" “Sphere of subjectivity

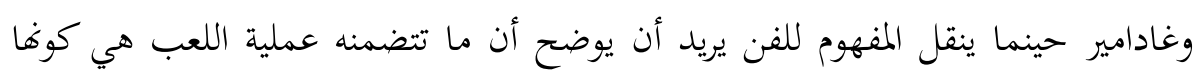

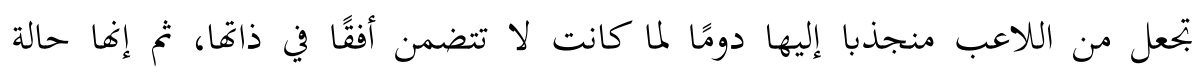

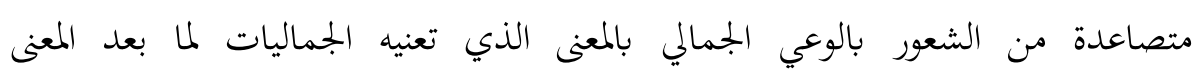

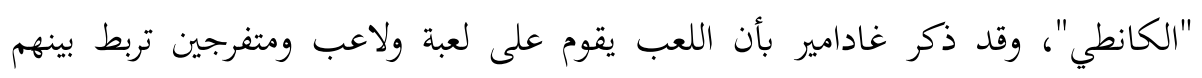

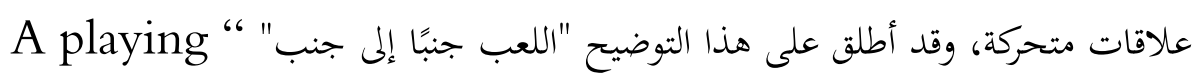

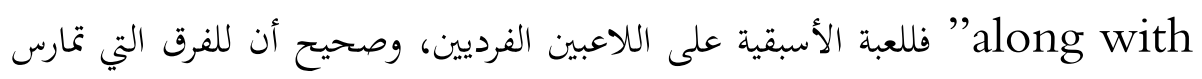

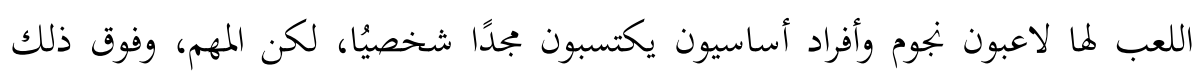

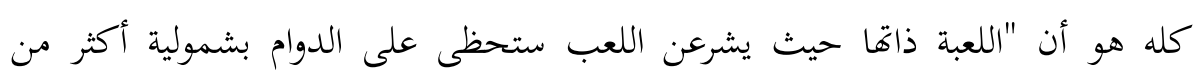


سلوك اللاعبين وتصرفاةم" (Chris Lawn \& Niall Keane, 2011, p110)، ويجر غادامير هذا التشبيه على حدود الذاتية من حيث أشكال الفهم والفرد، فنسبة اللاعبين إلى بنية الفريق أو اللعبة ذاتا، كتلك التي للذات الفردية المفكرة حيث تعد مجرد جزء من عملية تأويلية أكبر يسميها "حلقات الدوائر التاريخية المغلقة" ، The closed circuits of historical life

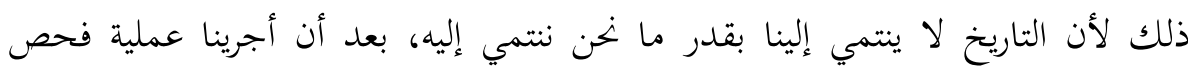

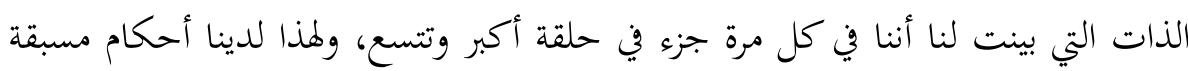
تشكل حقيقة وجودنا التاريخي. وهي متمثلة في اللغة والعادات والتقاليد.

11- منطق السؤال والجواب: The Logic of Question and Answer

بالأساس كان كولينجوود (1889-1943) هو من ابتكره عندما أصر في دراسته للآثار البريطانية "بريطانيا الرومانية" “Roman Britain على البحث بالسؤال

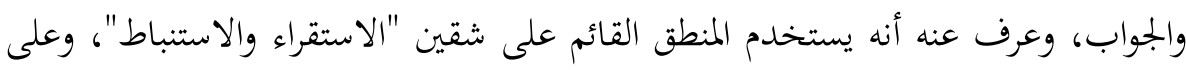
أية حال، فإنه تم النظر إلى أن "منطق السؤال والجواب" على أنه منطق يقابل المنطق الصوري التقليدي ويضاده، وقد تلقف غادامير "منطق السؤال والجواب" موظفًا إياه كإجراء لفهم النصوص التاريخية واستنطاقها، فكل نص صار موضوعًا للتأويل هو في الحقيقة نصٌّ

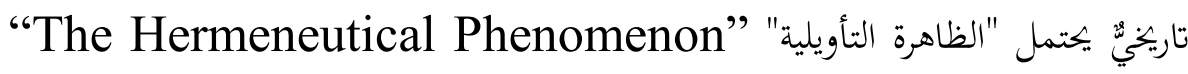
وعليه عند استعراضه يظل نصًا يطرح سؤاًا بغية الوصول لمعنى يلتقي فيه أفق المؤول وأفق

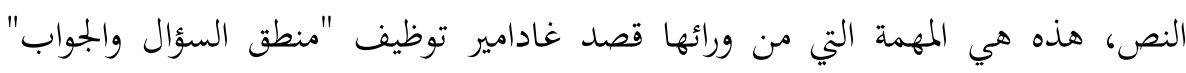
والنتيجة المرجوة من ورائه بوجه خاص فهم النصوص التاريخية، فلن يحدث الفهم ما لم يتم

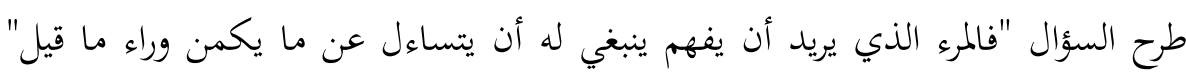


(Gadamer, 2006, p.363)، وما يقع تحت فهمه عليه أن يتصوره كإجابة عن سؤال طرحه حتى يتمكن من إعادة بنائه بما يضفيه من فرضيات تعتمل في مخيلته وتوقعات يسعى للوصول إليها إن كان قارئً نموذجيًا، فالقارئ النموذجي هو الذي يكون "قادرًا على أن يتحرك تأويليًا كما تحرك المؤلف توليديًا" (امبيرتو ايكو، 2007، ص22)، بمعنى أنه يجري فهمًا كما لو أنه سأل مسكوت النص من خلال تفكيك أبنيته وإعادة تركيبه حتى تتحقق له القراءة البناءة التوليدية.

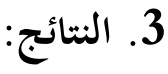

مما سبق نستنتج أن مهمة تتبع سيرة المصطلحات بقدر ما هي رائعة، وما فيها من متعة، فإِها في الوقت نفسه تنطلي على قدرٍٍ لا بأس به من التعقيد والصعوبة لكوها تقصد الوقوف على حقيقتها، وأن دراسة أي مصطلح تستلزم الوقوف على بنيته وكنهها، وبالتالي لابد من السؤال عن نشأته وظروف تكوينه ضمن مسار التاريخ انطلاقا من مهده الأول، وكذلك ضرورة الرجوع للظروف التي دفعت لسبكه وصياغته بل حتى الدوافع التي سيقت لأجله.

كما استنتجا أن مصطلحات غادامير الهرمنيوطيقية تتسم بالديناميكية الحركية المتواصلة بين الذات والموضوع من جهة، والذات والآخر من جهة ثانية، ولا تعرف السكون وتحيل إلى الحركة الأساسية للوجود الإنساني المنفعل المنطوي على التاريخ واستغراق الخبرة لإحداث حركة فهم شاملة.

ومما لا يدع مجالًا للشك أن غادامير حاول من خلال مصطلحاته إسقاط فرضية النشاط المستقل للوعي، فكل وعي يتشارك مع غيره طالما هناك قاسم مشترك بينهم متمثل 


\section{في اللغة، مما يفتح الباب أمام التأويل الذي بدوره يفتح باب الإمكان لإجراء التحاور والاستكشاف والدفع نحو الإنتاجية والإبداع.}

$$
\begin{aligned}
& \text { المراجع } \\
& \text { أولا: المراجع العربية } \\
& \text { إيكو أمبيرتو (2007). العلامة، تحليل المفهوم وتاريخه، (ترجمة سعيد بنكراد)، المركز } \\
& \text { الثقافي العربي، الدار البيضاء، ط1. } \\
& \text { ابن جني عثمان (1981). الخصائص، تحقيق محمد علي النجار، ط3، الهيئة المصرية }
\end{aligned}
$$

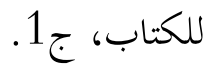

$$
\begin{aligned}
& \text { القاضي محمد "إشراف" (2010). معجم السرديات، عمل جماعي، دار الملتقى، المغرب، } \\
& \text {.1. } \\
& \text { ثانيًا:المراجع الأجنبية: - م }
\end{aligned}
$$

Barthes, R., (1970) Empire des signes, éd, Flammarion, Paris.

Fodor Janet, (1977) Semantics, Theories of Meaning in Generative Grammar, Crowell, New York.

Gadamer, H.G., (2004) Century of Philosophy, Hans Georg Gadamer in Conversation with Riccardo Dottori, (London: Continuum).

Gadamer H.G., (2006) Truth and Method, Eng Trans by: Joel Weinsheimer and G. Marshall, Second Revised Edition, Continuum, London, New York. 
Lawn Chris \& Keane Niall, (2011) The Gadamer Dictionary, Continuum International Publishing Group, London. 